\title{
Lipocalin 2 Suppresses Ocular Inflammation by Inhibiting the Activation of NF-k $\beta$ Pathway in Endotoxin-Induced Uveitis
}

\author{
Wenyi Tanga Jun Ma ${ }^{b} \quad$ Ruiping Gu ${ }^{a} \quad$ Xinyi Ding ${ }^{a} \quad$ Boya Leia ${ }^{a}$ Xin Wang ${ }^{a}$ \\ Hong Zhuang ${ }^{\mathrm{a}}$ Gezhi Xu ${ }^{\mathrm{a}, \mathrm{c}}$
}

aDepartment of Ophthalmology, Eye and ENT Hospital of Fudan University, Shanghai 'Research Center, Eye and ENT Hospital of Fudan University, Shanghai ‘Shanghai Key Laboratory of Visual Impairment and Restoration, Fudan University, Shanghai, China

\section{Key Words}

Lipocalin 2 - Ocular inflammation • Endotoxin-induced uveitis • Müller cells • NF-k $\beta$

\begin{abstract}
Background/Aims: Lipocalin 2 (LCN2), an important mediator of a variety of cellular processes, is involved in regulating the inflammatory response, but its roles in different inflammatory diseases are controversial. Because the role of LCN2 in ocular inflammation has been unclear until now, we explored the function of LCN2 in lipopolysaccharide (LPS)-induced ocular inflammation in vivo and in vitro. Methods: Endotoxin-induced uveitis (EIU) was induced in male Sprague Dawley rats by the intravitreal injection of LPS. The expression and location of LCN2 in the retina were detected with western blotting and immunohistochemistry, respectively. We determined the clinical scores for anterior inflammation, quantified the infiltrated inflammatory cells, and measured the pro-inflammatory factors to determine the anti-inflammatory effects of LCN2 in EIU eyes. Cultured primary rat Müller cells were stimulated with LPS and the expression and secretion of LCN2 were measured with real-time PCR, western blotting, and an ELISA. After Müller cells were cotreated with LPS and LCN2 or PBS, the expression and secretion of TNF- $\alpha$, IL- 6 , and MCP-1 were examined with realtime PCR, western blotting, and ELISAs. Western blotting and immunofluorescence were used to detect the phosphorylation and cellular distribution of nuclear factor kappaB (NFKB) subunit p65. Results: In EIU, the expression of LCN2 was significantly upregulated in the retina, especially in the outer nuclear layer (mainly composed of Müller cells). LPS stimulation of cultured Müller cells also markedly elevated LCN2 expression. Intravitreal injection of LCN2 significantly reduced the clinical scores, inflammatory infiltration, and protein leakage in EIU, which correlated with the reduced levels of proinflammatory factors in the aqueous humor
\end{abstract}

W. Tang and J. Ma contributed equally to this work.

Gezhi Xu

Department of Ophthalmology, Eye and ENT Hospital of Fudan University

83 Fenyang Road, Shanghai 200031, (China)

Tel.+8602164377134 Fax +8602164377151, E-Mail xugezhi@sohu.com 
and retina. LCN2 treatment also reduced the expression and secretion of TNF- $\alpha$, IL-6, and MCP-1 in LPS-stimulated Müller cells. LCN2 inhibited the inflammatory response by inhibiting the phosphorylation and translocation of NF-KB p65. Conclusions: LCN2 protects against ocular inflammation, at least in part, by negatively regulating the activation of the NF-KB signaling pathway. LCN2 may be a promising anti-inflammatory therapy for ocular diseases, such as uveitis.

(C) 2018 The Author(s)

Published by S. Karger AG, Basel

\section{Introduction}

Uveitis, a common ocular inflammatory disease, leads to 5\%-10\% visual impairment in the world [1]. It is not only triggered by infectious agents, such as bacteria and viruses, but also manifests as part of systemic immune diseases, such as juvenile idiopathic arthritis and Behçet's disease [2]. The inflammation can compromise both the anterior and posterior segments of the eye. Endotoxin-induced uveitis (EIU) is an animal model widely used to study acute ocular inflammation, including uveitis, and can be established by the systemic or topical application of lipopolysaccharide (LPS), a component of the Gram-negative bacterial outer membrane $[3,4]$. During uveitis, the blood-ocular barrier (BOB) can be disrupted and inflammatory cells, such as macrophages and neutrophils, infiltrate the eye $[5,6]$. Inflammatory mediators, such as tumor necrosis factor $\alpha$ (TNF- $\alpha$ ), interleukin 6 (IL6), and monocyte chemoattractant protein 1 (MCP-1) also participate in the pathogenesis of EIU $[7,8]$. Anti-inflammatory agents, including corticosteroids and immunosuppressants, are often used in the treatment of uveitis to control inflammation and prevent relapse [9]. However, the long-term use of these drugs can induce various adverse reactions, including glaucoma, cataract, and increased susceptibility to infection [10]. Therefore, the search for novel regulatory factors involved in the progression of EIU is essential to the development of appropriate therapeutic strategies.

Lipocalin 2 (LCN2), a secretory glycoprotein, belongs to the lipocalin family, the members of which bind various hydrophobic molecules, including retinoids, steroids, and fatty acids [11]. LCN2 was first identified as a bacteriostatic factor, and recent evidence has identified its roles in diverse cellular processes, including cell survival and death, migration, and morphology $[12,13]$. LCN2 is also reported to be an acute phase protein and its expression is induced in many organs in response to injury or inflammatory stimuli $[14,15]$. However, conflicting roles for LCN2 in different inflammatory diseases have been reported. Several in vivo studies reported that LCN2 drives the inflammatory responses in pneumonia, psoriasis, and Alzheimer's disease [16-18], whereas other studies have demonstrated that LCN2 exerts an anti-inflammatory activity in sepsis, tuberculosis, and autoimmune encephalomyelitis [19-21]. However, there have been few studies of the role of LCN2 in ocular diseases, especially uveitis.

We undertook this study to investigate the effects of LCN2 in LPS-induced ocular inflammatory models and the regulatory mechanisms involved. Our results show that LCN2 is upregulated in the retina and Müller cells in EIU and acts as an endogenous antiinflammatory mediator. LCN2 not only ameliorated the inflammatory manifestation in vivo but also reduced the release of inflammatory mediators in Müller cells in vitro, at least in part by inhibiting the activation of the NF- $\kappa B$ signaling pathway. These data together suggest that LCN2 is a potential therapeutic agent for the treatment of acute ocular inflammation, including uveitis.

\section{Materials and Methods}

Animals

All protocols were approved by the Animal Ethics Committee of the Eye and Ear Nose Throat Hospital of Fudan University, China, and were performed in accordance with the statement of ARVO on the Use of 


\section{Cellular Physiology Cell Physiol Biochem 2018;46:375-388 \begin{tabular}{l|l} 
and Biochemistry Published online: March 28, 2018 & $\begin{array}{l}\text { (c) } 2018 \text { The Author(s). Published by S. Karger AG, Basel } \\
\text { www.karger.com/cpb }\end{array}$
\end{tabular}}

Tang et al.: LCN2 Suppresses Ocular Inflammation in EIU

Animals in Research. Adult male Sprague Dawley rats $(n=180)$ from Slac Laboratories (Shanghai, China), weighing 180-200 g, were housed under a light/dark cycle of $12 \mathrm{~h} / 12 \mathrm{~h}$, with access to food and water ad libitum. The rats were anesthetized with an intraperitoneal injection of ketamine $(80 \mathrm{mg} / \mathrm{kg})$ and xylazine $(10 \mathrm{mg} / \mathrm{kg})$ during examination, and were killed by cervical dislocation at the end of the experiment.

\section{Induction of EIU and the experimental protocol}

After anesthesia, the rats were divided randomly into four treatment groups: (1) phosphate-buffered saline (PBS); (2) LCN2; (3) LPS+PBS; and (4) LPS+LCN2. To induce EIU, each right rat eye received a single intravitreal injection by microsyringe (Hamilton Bonaduz AG, Bonaduz, Switzerland) of $250 \mathrm{ng}$ of LPS from Escherichia coli 0111:B4 (Sigma-Aldrich, St. Louis, MO, USA) in $2 \mu$ of PBS. The control right rat eyes were intravitreally injected with $2 \mu \mathrm{l}$ of PBS. The rats in the LCN2 treatment group were injected intravitreally with LCN2 (1 $\mu$ g in $2 \mu \mathrm{l}$ of PBS; R\&D Systems, Minneapolis, MN, USA) or the same amount of PBS concurrently with LPS or PBS, as planned. No injection was given into the left eyes. At various time points after injection, the rats were killed under anesthesia and their eyes were enucleated. The retinal tissues were isolated and snap-frozen at $-80^{\circ} \mathrm{C}$ until analysis. The aqueous humor $(\mathrm{AqH})$ in the anterior chamber was collected with a microsyringe, and centrifuged at $300 \times g$ for 5 min at $4{ }^{\circ} \mathrm{C}$ to separate the supernatant and the cell pellet. The protein concentration in the supernatant was measured with a BCA Protein Assay Kit (Beyotime, Jiangsu, China), and the remaining supernatant was stored at $-80^{\circ} \mathrm{C}$ for later analysis. The pellet was suspended in PBS, and the number of cells was counted with a hematocytometer.

\section{Clinical scoring}

The clinical signs of anterior ocular inflammation in each group were examined with biomicroscopy at 24,48 , and $72 \mathrm{~h}$ after the intravitreal injection of LPS, before sampling. The severity of inflammation was graded blindly according to a previously reported scoring system [4] (Table 1).

\section{Histopathological evaluation}

The enucleated eyes were fixed in $4 \%$ paraformaldehyde for $24 \mathrm{~h}$ at room temperature, and then stored in $70 \%$ alcohol at $4{ }^{\circ} \mathrm{C}$ until embedded in paraffin. Serial sagittal sections ( $5 \mu \mathrm{m}$ thick) were cut through the optic nerve head and stained with hematoxylin and eosin (H\&E). The anterior chamber, iris-ciliary body, vitreous, and retina were examined with light microscopy (Leica Microsystems, Wetzlar, Hesse-Darmstadt, Germany). Only one section of each eye was chosen, and each group contained three eyes. Infiltrating cells were counted by an investigator blinded to the treatment group.

\section{Immunohistochemistry}

The corneas and lenses of the enucleated eyes were removed, and the remaining eye cups were fixed in $4 \%$ paraformaldehyde at $4{ }^{\circ} \mathrm{C}$ overnight. The eye cups were dehydrated in 20\%-30\% graded sucrose, embedded in optimal cutting temperature (OCT) compound (Tissue-Tek; Tokyo, Japan), and cryosectioned to sagittal sections (10 $\mu \mathrm{m}$ thick). The sections were incubated with $5 \%$ goat serum and $0.3 \%$ Triton X-100 in PBS for $1 \mathrm{~h}$ at room temperature, and were then incubated overnight at $4{ }^{\circ} \mathrm{C}$ with a mixture of primary antibodies: rabbit anti-LCN2 antibody (ab63929, diluted 1:100, Abcam, Cambridge, UK) and mouse antiglutamate synthase (anti-GS) antibody (ab64613, diluted 1:100, Abcam). After the sections were washed with PBS, they were incubated with a mixture of the corresponding secondary antibodies (A-11008, A-21422, diluted 1:1000, Invitrogen, Garlsbad, CA, USA) for $1 \mathrm{~h}$ at room temperature. The sections were rinsed with PBS, counterstained with 4,6-diamidino2-phenylindole (DAPI; Sigma-Aldrich) for $5 \mathrm{~min}$, and examined with a laser confocal microscope (Leica Microsystems).

Table 1. Scoring system for endotoxininduced uveitis in rat eyes

\begin{tabular}{lcc}
\hline Clinical sign & Grade of sign & Score \\
\hline Iris hyperemia & Absent & 0 \\
& Mild & 1 \\
& Moderate & 2 \\
Exudate in anterior chamber & Severe & 3 \\
& Absent & 0 \\
& Small & 1 \\
Hypopyon & Large & 2 \\
Pupil & Absent & 0 \\
& Present & 1 \\
Maximum possible score & Normal & 0 \\
& Miosed & 1 \\
& & 7
\end{tabular}

Table 2. Primer sequences used for real-time PCR in this study

\begin{tabular}{lcc}
\hline Gene & Forward $\left(5^{\prime} \rightarrow 3^{\prime}\right)$ & Reverse $\left(5^{\prime} \rightarrow 3^{\prime}\right)$ \\
\hline LCN2 & AACGTCACTTCCATCCTCGT & CCATGGCAAACTGGTCGTAG \\
TNFA & CCGATTTGCCATTTCATACCAG & TCACAGAGCAATGACTCCAAAG \\
IL6 & GTTGCCTTCTTGGGACTGATG & TACTGGTCTGTTGTGGGTGGT \\
MCP1 & GTCGGCTGGAGAACTACAAGA & GTGCTGAAGTCCTTAGGGTTG \\
IFNG & CGTCTTGGTTTGCAGCTCT & CGTCCTTTTGCCAGTTCCTC \\
CXCL10 & CAAGTGCTGCTGTCGTTCTC & TCTCAACATGCGGACAGGAT \\
IL1B & CCTGTGTGATGAAAGACGGC & TATGTCCCGACCATTGCTGT \\
IL17 & CTTCTGTGATCTGGGAGGCA & GGCGGACAATAGAGGAAACG \\
GAPDH & ACAGCAACAGGGTGGTGGAC & TTTGAGGGTGCAGCGAACTT \\
\hline
\end{tabular}




\section{Cellular Physiology Cell Physiol Biochem 2018;46:375-388 \begin{tabular}{l|l|l} 
and BOI: 10.1159/000488472 & $\begin{array}{l}\text { C) } 2018 \text { The Author(s). Published by S. Karger AG, Basel } \\
\text { www.karger.com/cpb }\end{array}$
\end{tabular}}

Tang et al.: LCN2 Suppresses Ocular Inflammation in EIU

Primary rat retinal Müller cell isolation, culture, and treatment

Müller cells were isolated from the retinas of neonatal rats, as reported previously [22]. Briefly, the retinas of 20 rats were collected by microdissection under sterile conditions and digested with $0.25 \%$ trypsin for $5 \mathrm{~min}$. After the trypsin was deactivated and the samples centrifuged at $500 \times \mathrm{g}$ for $5 \mathrm{~min}$, the cell pellets were resuspended in Dulbecco's modified Eagle's medium/nutrient mixture F-12 (Gibco, New York, NY, USA) supplemented with $20 \%$ fetal bovine serum (Gibco) and $1 \%$ penicillin/streptomycin (SigmaAldrich), plated in $75 \mathrm{~cm} 2$ culture flasks, and incubated at $37^{\circ} \mathrm{C}$ in a humidified atmosphere containing $5 \%$ C02. Cells from passages 2-4 were used for the experiments. LPS or LCN2 was first dissolved in PBS (1 mg/ $\mathrm{ml}$ ) and diluted with culture medium to $0.01,0.1$, and $1 \mu \mathrm{g} / \mathrm{ml}$ or to $0.5,1$, and $2 \mu \mathrm{g} / \mathrm{ml}$, respectively. The Müller cells were cultured in six-well plates and then simultaneously stimulated with LPS and/or LCN2 at the indicated concentrations for the indicated times. Equal amounts of PBS were added to the culture medium as the controls. After stimulation, the cells and supernatants were harvested.

\section{Immunocytofluorescence}

Müller cells were seeded on coverslips in 24-well plates, and then simultaneously stimulated with 1 $\mu \mathrm{g} / \mathrm{ml} \mathrm{LPS}$ and/or $1 \mu \mathrm{g} / \mathrm{ml} \mathrm{LCN} 2$ for $1 \mathrm{~h}$. After stimulation, the cells were washed with PBS and then fixed with $4 \%$ paraformaldehyde for $15 \mathrm{~min}$. After the cell membranes were permeabilized with $0.3 \%$ Triton $\mathrm{X}-100$, they were blocked with $5 \%$ goat serum for $1 \mathrm{~h}$ at room temperature and then incubated overnight at $4{ }^{\circ} \mathrm{C}$ with the following primary antibodies: rabbit anti-GS antibody (ab49873, diluted 1:100; Abcam), rabbit anti-NF- $\kappa B$ p65 antibody (4764S, diluted 1:100; Cell Signaling Technology, Beverly, MA, USA), or rabbit anti-NF- $\kappa$ B phospho-p65 antibody (3033S, diluted 1:100; Cell Signaling Technology). The coverslips were then washed three times with PBS and incubated with the corresponding secondary antibodies (A11008, A-21428, diluted 1:1000, Invitrogen) for 1 hour at room temperature. After three washes with PBS, the cells were counterstained with DAPI (Sigma-Aldrich) for $5 \mathrm{~min}$. The coverslips were visualized and photographed with fluorescence microscopy (Leica Microsystems).

\section{Western blotting}

The retinal tissues or Müller cells were mixed with RIPA buffer (Beyotime), homogenized, incubated on ice for $30 \mathrm{~min}$ and centrifuged at $12,000 \times \mathrm{g}$ for $15 \mathrm{~min}$ at $4^{\circ} \mathrm{C}$. The nuclear proteins of Müller cells and retinal tissues were extracted using the NE-PER Nuclear and Cytoplasmic Extraction Reagents (Thermo Scientific, Rockford, IL, USA). The protein concentration in each sample was measured with a BCA Protein Assay Kit (Beyotime). An equal amount of protein $(40 \mu \mathrm{g})$ from each sample was loaded onto a sodium dodecyl sulfate polyacrylamide gel and separated with electrophoresis, and transferred to polyvinylidene difluoride membrane (Millipore, Billerica, MA, USA). The membranes were blocked in 5\% skim milk and then incubated overnight at $4{ }^{\circ} \mathrm{C}$ with the following primary antibodies: rabbit anti-LCN2 (ab63929, diluted 1:400; Abcam), rabbit anti-glial fibrillary acidic protein (ab68428, anti-GFAP; diluted 1:1000; Abcam), rabbit anti-TNF- $\alpha$ (ab6671, diluted 1:500; Abcam), rabbit anti-IL-6 (21865-1-AP, diluted 1:300; Proteintech), rabbit anti-MCP-1 (ab25124, diluted 1:2000; Abcam), rabbit anti-NF-кB p65 (4764S, diluted 1:1000; Cell Signaling Technology), rabbit anti-NF-кB phospho-p65 (Ser536) (3033S, diluted 1:1000; Cell Signaling Technology), mouse anti- $\beta$-actin (ab6276, diluted 1:1000; Abcam), rabbit anti-H3 (4499S, diluted 1:1000; Cell Signaling Technology), or rabbit anti-glyceraldehyde 3-phosphate dehydrogenase (10494-1-AP, anti-GAPDH; diluted 1:1000; Proteintech). The membranes were incubated with the corresponding horseradish-peroxidaseconjugated secondary antibodies (SA00001-2, SA00001-1, diluted 1:5000, Proteintech) for $1 \mathrm{~h}$ at room temperature. The blots were developed with Pierce ECL Western Blotting Substrate (Thermo Scientific), and analyzed with the Kodak Digital Imaging System (Kodak, Rochester, NY, USA).

\section{Real-time PCR}

Total RNA was extracted from Müller cells with TRIzol Reagent (Invitrogen), according to the manufacturer's instructions. The PCR primers were synthesized by Tsingke Biological Technology (Shanghai, China) based on the mRNA sequences published in the National Center for Biotechnology Information database, and are listed in Table 2. Complementary DNA (cDNA) was generated with the PrimeScript RT reagent Kit (Takara, Shiga, Japan). Real-time PCR was performed with a LightCycler 480 II real-time PCR instrument (Roche, Basel, Switzerland) with $20 \mu \mathrm{L}$ PCR mixtures, which contained $4 \mu \mathrm{L}$ of cDNA, $10 \mu \mathrm{L}$ of $2 \times$ LightCycler 480 SYBR Green I Master Mix (Roche), $0.4 \mu \mathrm{L}$ of the forward primer $(100 \mu \mathrm{M}), 0.4 \mu \mathrm{L}$ of the 


\section{Cellular Physiology Cell Physiol Biochem 2018;46:375-388 \begin{tabular}{l|l} 
and Biochemistry Published online: March 28, 2018 & $\begin{array}{l}\text { (c) } 2018 \text { The Author(s). Published by S. Karger AG, Basel } \\
\text { www.karger.com/cpb }\end{array}$
\end{tabular} \\ Tang et al.: LCN2 Suppresses Ocular Inflammation in EIU}

reverse primer $(100 \mu \mathrm{M})$ and $5.2 \mu \mathrm{L}$ of nuclease-free water. The thermal cycling conditions were $95^{\circ} \mathrm{C}$ for 10 min, followed by 40 cycles of $95^{\circ} \mathrm{C}$ for $30 \mathrm{~s}$ and $60^{\circ} \mathrm{C}$ for $30 \mathrm{~s}$, and the melting curve profiles were generated at the end. The expression level of each mRNA was normalized to that of Gapdh mRNA and calculated with the $2^{-\Delta \Delta \mathrm{Ct}}$ method.

\section{Enzyme-linked immunosorbent assays (ELISAs)}

The concentrations of LCN2 in cell culture media and those of TNF- $\alpha$, IL-6, and MCP-1 in the AqH and cell culture media were quantified with the corresponding ELISA kits (Rat LCN2 ELISA Kit, ab119602; Rat TNF- $\alpha$ ELISA Kit, ab100785; Rat IL-6 ELISA Kit, ab100772; Rat MCP-1 ELISA Kit, ab100777; Abcam), according to the manufacturer's instructions.

\section{Statistical analyses}

The data were analyzed with the SPSS 21.0 software (Chicago, IL, USA). All values are expressed as the means \pm SEM of at least three independent experiments. The statistical analysis was performed by comparing the means of different groups with Student's unpaired or paired two-tailed $t$ test, or one-way ANOVA followed by Tukey's multiple-comparisons test. A $P$ value $<0.05$ was considered statistically significant.

\section{Results}

Expression of LCN2 is upregulated in the retina and Müller cells in EIU

EIU is a classical model for the study of acute ocular inflammation [3]. As shown in Fig. 1a, an intravitreal injection of 250 ng of LPS caused iris hyperemia, protein exudation, hypopyon, and miosed pupil in the anterior segment. H\&E staining revealed marked inflammatory cell infiltration in the iris-ciliary body region and the posterior vitreous cavity $24 \mathrm{~h}$ after the intravitreal injection of LPS (Fig. 1b), and the mRNA levels of TNF- $\alpha$, a well-known marker of ocular inflammation [23], were also significantly increased in the retina by LPS (Fig. 1c). These results demonstrate that the EIU model was successfully established with the intravitreal injection of LPS.

To investigate whether LCN2 participates in regulating ocular inflammation, we first examined its expression in response to EIU. The expression of LCN2 was significantly elevated in the retina, one of the main tissues affected by uveitis [24], from 8 $\mathrm{h}$ poststimulation (Fig. 1d). To explore the cellular localization of LCN2 in the

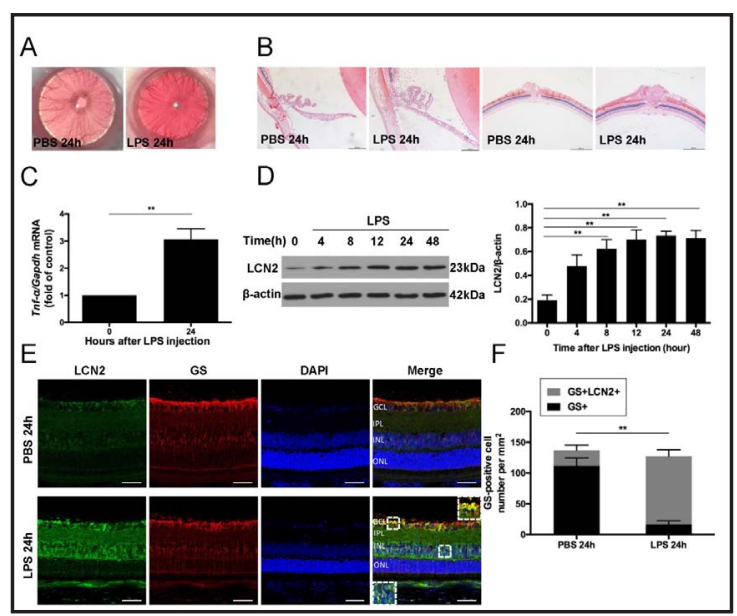

Fig. 1. Induction of EIU with intravitreal LPS injection and LCN2 upregulation and localization in the retina during EIU. (A) Clinical signs of uveitis in the PBStreated group and LPS-treated group at $24 \mathrm{~h}$, including iris hyperemia, fibrinous exudation, and hypopyon. (B) Infiltrating inflammatory cells in the iris ciliary-body and the vitreous cavity in the PBS-treated group and LPS-treated groupat $24 \mathrm{~h}$, detected with H\&E staining. (C) Real-time PCR detection of TNF- $\alpha$ mRNA in retinal tissues at $24 \mathrm{~h}$. Gapdh mRNA was used as the internal control. Student's unpaired two-tailed $t$ test was used. (D) Western blotting analysis of LCN2 protein in the retina $0,4,8,12,24$, and $48 \mathrm{~h}$ after intravitreal LPS injection. Quantification of the band intensities, after normalization to $\beta$-actin. One-way ANOVA with Tukey's multiple-comparisons test was used. (E) Double immunofluorescent staining of LCN2 (green) and GS (red) in sagittal sections of the retina $24 \mathrm{~h}$ after intravitreal LPS injection. Blue indicates DAPI-stained nuclei. Magnified boxes $(2 \times)$ show colocalization of LCN2 and Müller cells. GCL: ganglion cell layer; IPL: inner plexiform layer; INL: inner nuclear layer; ONL: outer nuclear layer. Scale bar: $50 \mu \mathrm{m}$. (F) Quantification of fluorescent images of the colocalization of LCN2 and GS. Paired $t$ test was used. $\mathrm{n}=3$ for each group. ${ }^{*} P<0.05,{ }^{* *} P<0.01$. 
Fig. 2. LCN2 alleviated clinical signs of uveitis in the anterior segment and reduced inflammatory cell infiltration in the anterior and posterior segments of EIU rat eyes. (A) Representative biomicroscopic images of the anterior segments in different treatment groups (PBS, LCN2, LPS+PBS, and LPS+LCN2) 0, 24, 48, and 72 $\mathrm{h}$ after LPS injection. (B) Clinical scores for the different treatment groups at $0,24,48$, and $72 \mathrm{~h}$ after LPS injection. Scores were evaluated by a blinded observer, according to the scoring system. One-way ANOVA with Tukey's multiple-comparisons test was used. $n=6$ for each group. (C-D) H\&E staining showed infiltrating inflammatory cells in the iris-ciliary body region and the posterior vitreous cavity in the LPS+PBS and LPS+LCN2 groups $0,24,48$, and $72 \mathrm{~h}$ after treatment. Scale bars: $200 \mu \mathrm{m}$ and $500 \mu \mathrm{m}$, respectively. (E-F) Numbers of infiltrating inflammatory cells in the iris-ciliary body region and the posterior vitreous cavity per section were evaluated by a blinded observer. One-way ANOVA with Tukey's multiple-comparisons test was used. $\mathrm{n}=3$ for each group. ${ }^{*} P<0.05,{ }^{* *} P<0.01$.

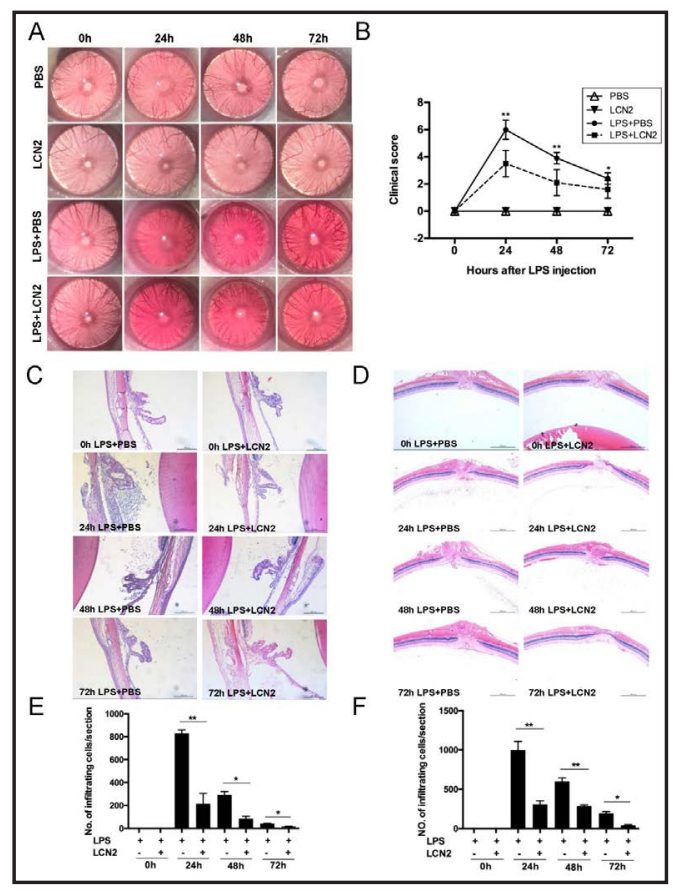

retina, double immunofluorescent staining for LCN2 and glutamate synthase (GS), a marker of Müller cells [25], was performed $24 \mathrm{~h}$ after the intravitreal injection of LPS (Fig. 1e). LCN2-positive cells also expressing GS were more obvious in the inner nuclear layer (INL) and ganglion cell layer (GCL) of the retinas in the LPS-treated eyes than in the PBS-treated eyes. The number of LCN2-positive Müller cells that were also positive for GS in the retinal sections increased significantly after LPS stimulation (Fig. 1f). These findings indicate that LCN2 expression is upregulated in the retina and Müller cells in EIU, and that reactive Müller cells may be one of the major cellular sources of LCN2 in the retina.

\section{Treatment with LCN2 protects against LPS-induced inflammation}

We next investigated the specific role of LCN2 in EIU using an exogenous recombinant LCN2 protein. The inflammation in the anterior chambers of the different groups was assessed with biomicroscopy at different time points after LPS challenge. The clinical scores were evaluated blindly, according to a previously reported scoring system [4] (Table 1). As shown in Fig. 2a, LPS injection induced clear inflammatory responses, such as iris hyperemia, protein exudation, and hypopyon, which peaked at $24 \mathrm{~h}$ and lasted for $72 \mathrm{~h}$. However, the inflammatory reactions triggered by LPS were markedly alleviated by LCN2 treatment. At 24,48 , and $72 \mathrm{~h}$ after treatment, the clinical scores in the LPS+LCN2 group were significantly lower than those in the LPS+PBS group (LPS+LCN2 group vs LPS+PBS group at $24 \mathrm{~h}: 6.00 \pm$ 0.24 vs $3.50 \pm 0.32$, respectively, $P<0.0001$; at $48 \mathrm{~h}: 3.90 \pm 0.19$ vs $2.10 \pm 0.43$, respectively, $p=0.005$; at $72 \mathrm{~h}: 2.40 \pm 0.19$ vs $1.60 \pm 0.29$, respectively, $p=0.0497$; Fig. $2 \mathrm{~b})$. These results suggest that LCN2 treatment reduces the clinical severity of EIU.

Because EIU is characterized by the breakdown of the BOB and inflammatory cell infiltration of the eyes, we examined the inflammatory cell infiltration with H\&E staining. As shown in Fig. 2, inflammatory cells were noticeably recruited into the eyes after LPS injection, especially at $24 \mathrm{~h}$ (Fig. 2c, 2d). However, the LCN2-treated eyes showed a significant reduction in infiltrating cells in the iris-ciliary body region and the posterior vitreous cavity compared with the eyes without LCN2 treatment at 24,48 , and $72 \mathrm{~h}$ after LPS injection. It is noteworthy that there was a $69.14 \%$ reduction in inflammatory cells in the iris ciliary body region and a $74.23 \%$ reduction in the posterior vitreous cavity in the LCN2-treated eyes at $24 \mathrm{~h}$ after LPS injection (Fig. 2e, 2f). These findings imply that LCN2 attenuates histopathological ocular inflammation. 
LCN2 inhibits the release of proinflammatory factors and represses their expression

Because the LPS-induced inflammation in the anterior segment of the eye peaked at $24 \mathrm{~h}$, we chose this time point to explore the protein concentration, cell numbers, and proinflammatory factor levels in the $\mathrm{AqH}$. The injection of LPS substantially increased the protein concentration and inflammatory cells in the $\mathrm{AqH}$, which were mitigated by LCN2 treatment (Fig. 3a, $3 \mathrm{~b})$. We also determined the amounts of TNF- $\alpha$, IL- 6 , and MCP- 1 released into the $\mathrm{AqH}$. These important proinflammatory factors were significantly increased in the iris-ciliary body during LPS-induced uveitis [26, 27]. As shown in Fig. 3c-3e, the concentrations of TNF- $\alpha$, IL-6, and MCP-1 in the AqH were significantly elevated 24 $\mathrm{h}$ after EIU induction, whereas treatment with LCN2 markedly reduced their levels. A western blotting analysis demonstrated that LPS challenge significantly induced the expression of TNF- $\alpha$, IL- 6 , and MCP-1 in the retina, which was clearly inhibited by LCN2 treatment at 24,48 , and $72 \mathrm{~h}$ after the intravitreal injection of LPS (Fig. $3 \mathrm{f}-3 \mathrm{~h}$ ). These results suggest that LCN2 mitigates the inflammation in the anterior segment and posterior segment of the eye.

LCN2 expression is upregulated in LPStreated Müller cells

Müller cells, the major glial cells in the retina, play an important role in retinal inflammation [28]. LPS-induced inflammation paralleled the reactive gliosis of the retinal Müller cells, because the expression of the gliotic marker GFAP was upregulated in a time-dependent manner

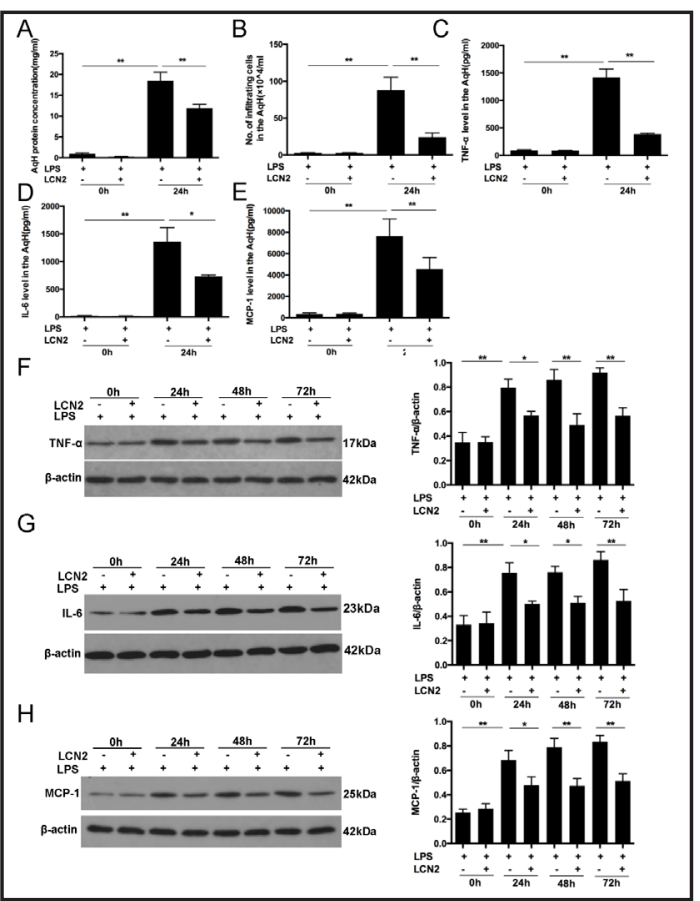

Fig. 3. LCN2 reduced the protein concentration, infiltrating cell number, and levels of proinflammatory factors in the $\mathrm{AqH}$ and reduced the expression of proinflammatory factors in the retinas of EIU eyes. (A-B) Protein concentrations and cell numbers in the AqH of the LPS+PBS group and LPS+LCN2 group were evaluated 0 and $24 \mathrm{~h}$ after LPS injection with the BCA method and cell counting, respectively. (C-E) Levels of TNF- $\alpha$, IL-6, and MCP1 in the AqH of the LPS+PBS group and LPS+LCN2 group were measured 0 and $24 \mathrm{~h}$ after LPS injection with ELISAs. (F-H) Western blotting analysis of TNF- $\alpha$, IL-6, and MCP-1 protein levels in the retinas of different groups (LPS+PBS, LPS+LCN2) at 0, 24, 48, and $72 \mathrm{~h}$ after LPS injection. Quantification of the band intensities after normalization to $\beta$-actin is presented. One-way ANOVA with Tukey's multiplecomparisons test was used. $\mathrm{n}=6$ for each group in A-E; $\mathrm{n}=3$ for each group in F-H. ${ }^{*} P<0.05,{ }^{* *} P<0.01$.

(Fig. 4a, 4b). Furthermore, the expression of LCN2 was significantly upregulated by LPS in the outer nuclear layer of the retina, where Müller cells are one of the main cellular components [29]. Therefore, we investigated the effects of LCN2 on LPS-induced inflammation in Müller cells. The purity of the primary cultured Müller cells was confirmed by detecting the marker protein GS with immunocytochemical staining (Fig. 4c). Upon LPS stimulation, the expression of GFAP in Müller cells increased markedly, in a dose-dependent manner (Fig. 4d), demonstrating that LPS activated Müller cells in vitro. The Müller cells were then exposed to different concentrations of LPS $(0,0.01$, 0.1 , or $1 \mu \mathrm{g} / \mathrm{ml}$ ) for $24 \mathrm{~h}$, or to $1 \mu \mathrm{g} / \mathrm{ml}$ LPS for different time periods $(0,4,8,24$ or $48 \mathrm{~h})$. The protein and mRNA expression of LCN2 induced by LPS were upregulated in a dose- and timedependent manner (Fig. 5a-5d). Similar results were obtained by measuring the LCN2 levels in the cell supernatant (Fig. 5e, 5f). These data show that LPS induces the acute expression and secretion of LCN2 in Müller cells.

\section{KARGER}




\section{Cellular Physiology Cell Physiol Biochem 2018;46:375-388 \begin{tabular}{l|l} 
and Biochemistry & DOI: 10.1159/000488472 \\
Published online: March 28, 2018 & $\begin{array}{l}\text { C } 2018 \text { The Author(s). Published by S. Karger AG, Basel } \\
\text { www.karger.com/cpb }\end{array}$
\end{tabular}

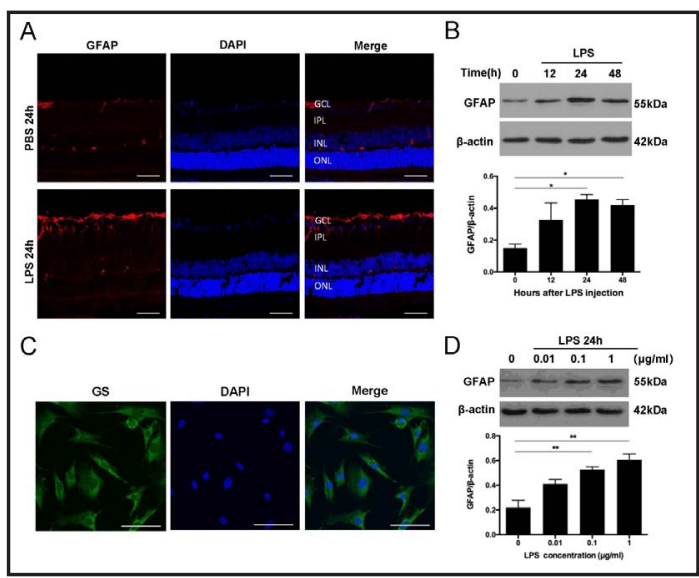

Fig. 4. Increased expression of GFAP in Müller cells after LPS stimulation. (A) Immunofluorescent imaging of GFAP (red), as a marker of Müller cells, in a retinal section at $24 \mathrm{~h}$. Blue indicates DAPIstained nuclei. GCL: ganglion cell layer; IPL: inner plexiform layer; INL: inner nuclear layer; ONL: outer nuclear layer. Scale bar: $50 \mu \mathrm{m}$. (B) Western blotting analysis showed that GFAP expression increased time-dependently after LPS stimulation ( $1 \mu \mathrm{g} / \mathrm{ml}$ ). Quantification of the band intensities after normalization to $\beta$-actin is presented. (C) Identification of primary Müller cells with immunofluorescence using the marker protein GS (green). Blue indicates DAPI-stained nuclei. Scale bar: $50 \mu \mathrm{m}$. (D) Western blotting analysis of GFAP protein expression in Müller cells $24 \mathrm{~h}$ after LPS $(0.01,0.1$, or $1 \mu \mathrm{g} / \mathrm{ml})$ stimulation. Quantification of the band intensities after normalization to $\beta$-actin is presented. One-way ANOVA with Tukey's multiple-comparisons test was used. $\mathrm{n}=3$ for each group. ${ }^{*} P<0.05,{ }^{* *} P<0.01$.

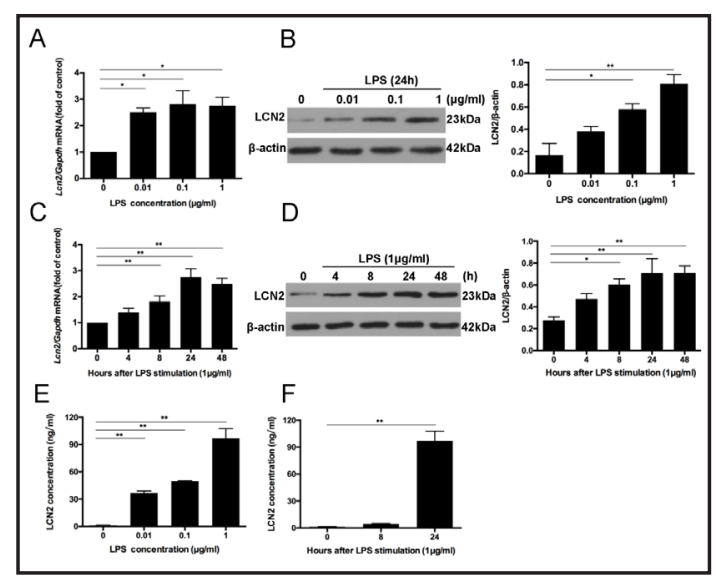

Fig. 5. LCN2 was upregulated in LPS-treated Müller cells. (A-B) Dose-dependent effect of LPS on LCN2 expression. Cells were treated with $0,0.01,0.1$, or $1 \mu \mathrm{g} / \mathrm{ml}$ LPS for $24 \mathrm{~h}$, and LCN2 protein and mRNA levels were analyzed with western blotting and real-time PCR, respectively. (C-D) Time-dependent effects of LPS on LCN2 expression. Cells were treated with $1 \mu \mathrm{g} / \mathrm{ml}$ LPS for $0,4,8,24$, or $48 \mathrm{~h}$, and LCN2 protein and mRNA levels were analyzed with western blotting and real-time PCR, respectively. (E-F) Supernatant concentrations of LCN2 after stimulation with different LPS concentrations for 24 $\mathrm{h}$ or stimulation with $1 \mu \mathrm{g} / \mathrm{ml}$ LPS for 0 , 8, or $24 \mathrm{~h}$ were measured with ELISAs. Quantification of the band intensities after normalization to $\beta$-actin is presented. Gapdh was used as the internal control for real-time PCR. One-way ANOVA with Tukey's multiple-comparisons test was used. $\mathrm{n}=3$ for each group in A-D; $\mathrm{n}=6$ for each group in $\mathrm{E}-\mathrm{F} .{ }^{*} P<0.05$, ${ }^{* *} P<0.01$.

\section{LCN2 suppresses LPS-induced expression of proinflammatory cytokines in Müller cells}

Various inflammatory cytokines and chemokines were significantly increased in Müller cells after LPS stimulation, among which TNF- $\alpha$, IL-6, and MCP-1 were particularly obvious (Fig. 6a). After treatment with different doses of LCN2 $(0.5,1$, or $2 \mu \mathrm{g} / \mathrm{ml})$, the LPS-induced expression of TNF-a, IL-6, and MCP-1 was suppressed in a dose-dependent manner at the protein level (Fig. $6 \mathrm{~b}-6 \mathrm{~d}$ ). LPS stimulation $(1 \mu \mathrm{g} / \mathrm{ml})$ also strongly induced the mRNA expression of TNF- $\alpha$, IL- 6 , and MCP- 1 , and enhanced their secretion into the supernatant, and these processes were antagonized by $1 \mu \mathrm{g} / \mathrm{ml}$ LCN2 (Fig. 6e-6j). These results indicate that LCN2 protects Müller cells against the inflammatory reactions induced by LPS.

LCN2 inhibits LPS-induced NF- KB p65 phosphorylation and nuclear translocation in Müller cells and retinal tissues

$\mathrm{NF}-\mathrm{\kappa B}$ is an important transcription factor that controls the expression of various genes involved in inflammation. Its activation, which is marked by the phosphorylation and nuclear translocation of the NF- $\mathrm{BB}$ subunit p65, increases the expression of many inflammatory cytokines and chemokines [30]. To determine the molecular mechanism 
Fig. 6. LCN2 suppressed the LPS-induced expression of TNF- $\alpha$, IL-6, and MCP-1 in Müller cells. (A) Real-time PCR analysis of inflammatory factor mRNAs (TNF- $\alpha$, IL-6, MCP-1, interferon $\gamma$ [IFN- $\gamma$ ], C-X-C motif chemokine ligand 10 [CXCL10], IL-1 $\beta$, IL-17) at $24 \mathrm{~h}$ after stimulation with $1 \mu \mathrm{g} /$ $\mathrm{ml}$ LPS. Gapdh mRNA was used as the internal control. Student's unpaired two-tailed $t$ test was used. (B-D) After cotreatment of cells with LCN2 $(0,0.5,1$, or $2 \mu \mathrm{g} / \mathrm{ml})$ and LPS $(1 \mu \mathrm{g} / \mathrm{ml})$ for 24 $h$, the TNF- $\alpha$, IL- 6 and MCP-1 protein levels were analyzed with western blotting. Quantification of the band intensities after normalization to $\beta$-actin is presented. (E-G) Real-time PCR data for TNF- $\alpha$, IL-6, and MCP-1 mRNAs in control or LPS-treated groups with or without LCN2 $(1 \mu \mathrm{g} / \mathrm{ml})$ at $24 \mathrm{~h}$. Gapd $h$ was used as the internal control for real-time PCR. (H-J) ELISAs were used to detect supernatant concentrations of TNF- $\alpha$, IL-6, and MCP-1 in the control and LPS-treated groups with or without LCN2 $(1 \mu \mathrm{g} / \mathrm{ml})$ at $24 \mathrm{~h}$. One-way ANOVA with Tukey's multiple-comparisons test was used. $\mathrm{n}=3$ for each group in A-G; $\mathrm{n}=6$ for each group in $\mathrm{H}-\mathrm{J}$. ${ }^{*} P<0.05,{ }^{* *} P<0.01$.

Fig. 7. LCN2 inhibited the activation of NF- $\kappa B$ p65 in LPS-stimulated Müller cells and retinal tissues. Müller cells were simultaneously treated with $1 \mu \mathrm{g} / \mathrm{ml}$ LPS and/or $1 \mu \mathrm{g} / \mathrm{ml}$ LCN2 for $1 \mathrm{~h}$ (A-D). Retinas of different groups (LPS + PBS, LPS + LCN2) at 0 and $1 \mathrm{~h}$ after LPS injection were harvested (E-F). (A-B) Intracellular localization of NF- $\mathrm{B}$ phospho-p65 (Ser536) and p65 was assessed with immunofluorescence in Müller cells. Scale bar: $50 \mu \mathrm{m}$. (C) Western blotting analysis of NF$\kappa B$ phospho-p65 (Ser536) and total p65 in Müller cells. Quantification of the band intensities after normalization to $\beta$-actin is presented. (D) Western blotting analysis of NF- $\kappa \mathrm{B}$ p65 in nuclear proteins of Müller cells. $\mathrm{H} 3$ were used as the loading control for the nuclear fractions. GADPH was used to exclude the possibility of cross contamination. Quantification of the band intensities after normalization to $\mathrm{H} 3$ is presented. (E) Western blotting analysis of NF- $\kappa$ B phospho-p65 (Ser536) and total p65 in retinal tissues. Quantification of the band intensities after normalization to $\beta$-actin is presented. (F) Western blotting analysis of NF$\kappa \mathrm{B}$ p65 in nuclear proteins of retinal tissues. H3 were used as the loading control for the nuclear fractions. GADPH was used to exclude the possibility of cross contamination. Quantification of the band intensities after normalization to H3 is presented. One-way ANOVA with Tukey's multiple-comparisons test was used. $\mathrm{n}=3$ for each group. ${ }^{*} P<0.05,{ }^{* *} P<0.01$.
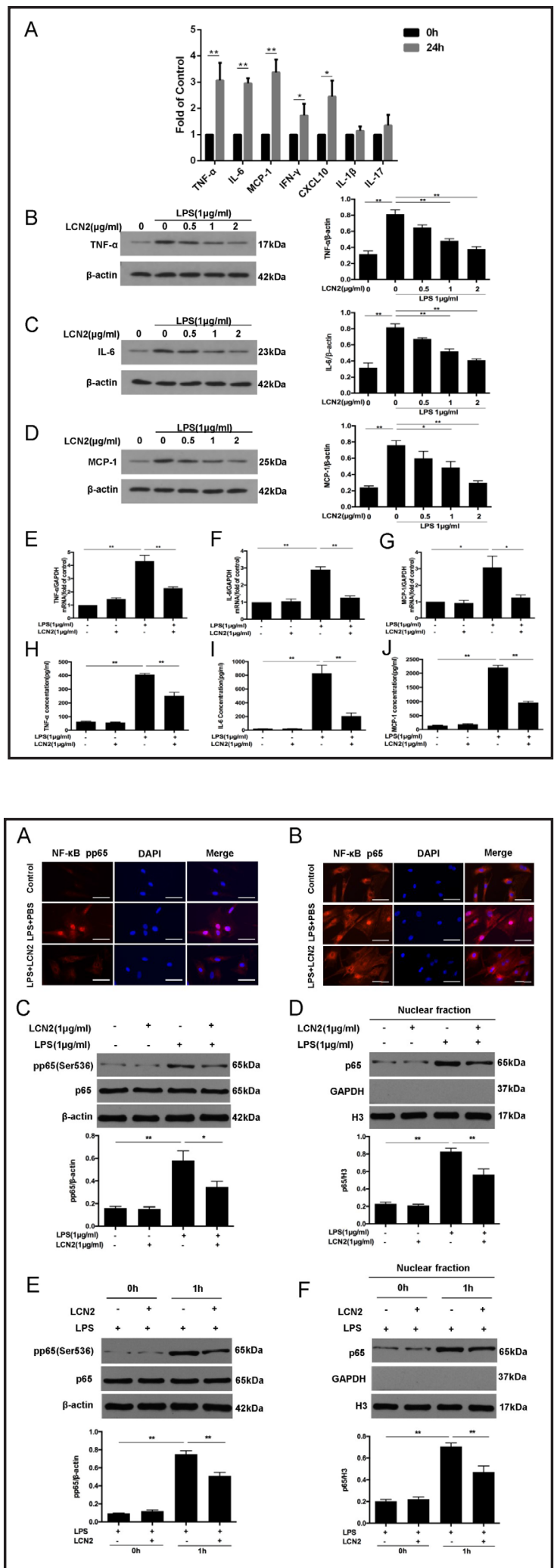

E

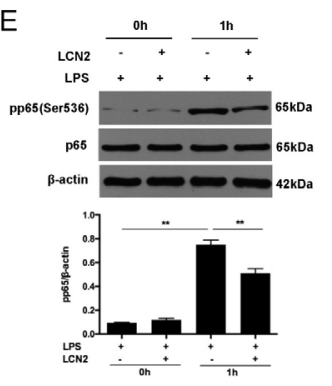


of the LCN2-inhibited inflammatory reactions, we investigated whether the activation of $\mathrm{NF}-\kappa \mathrm{B}$ is negatively regulated by LCN2. Immunofluorescent images showed that LCN2 treatment significantly reduced the level of phospho-p65 in the nucleus and inhibited the nuclear translocation of p65 (Fig. 7a, 7b). A western blotting analysis of the protein levels of phospho-p65 (at Ser536) in whole-cell lysates and the nuclear fraction of p65 confirmed the immunofluorescence results (Fig. 7c, 7d). We also examined the effects of LCN2 on the activation of NF- $\kappa B$ p65 in lysed rat retina. Our results showed that up-regulation of phospo-p65 (at Ser536) and nuclear translocation of p65 induced by LPS were significantly mitigated by LCN2 treatment (Fig. 7e, 7f), which is consistent with the findings from cultured Müller cells. These data suggest that LCN2 inhibits the inflammatory response induced by LPS by repressing the activation of the NF- $\kappa B$ signaling pathway.

\section{Discussion}

Uveitis is a prevalent health problem with potentially sight-threatening outcomes [2]. Commonly used anti-inflammatory drugs, such as corticosteroids, have many adverse effects [10]. Therefore, it is critical to develop more effective therapeutic strategies. In this study, we provide the first evidence that LCN2 is critically involved in acute retinal inflammation as an anti-inflammatory factor. Using a model of EIU, we found that although the expression of LCN2 was elevated in the retina and Müller cells, LCN2 treatment not only reduced the signs of anterior uveitis and lessened retinal damage in vivo, but also reduced the production of proinflammatory mediators, such as TNF- $\alpha$, IL-6, and MCP-1, in Müller cells. LCN2 exerted its anti-inflammatory effects by negatively regulating the activation of the NF- $\kappa B$ pathway. These results indicate that LCN2 might be utilized as an anti-inflammatory mediator in the treatment of ocular inflammatory diseases.

An important finding of our study is that the expression of LCN2 increased after LPS stimulation and protected the ocular tissues against the inflammatory reactions induced. Previous studies have shown that after LPS stimulation, Lcn2 as an acute phase protein is rapidly induced in various cells of the central nervous system, including astrocytes, microglia and endothelial cells [31-33]. Moreover, the expression of LCN2 was found to be markedly elevated in the brain and in cultured astrocytes at 4-8 $\mathrm{h}$ after exposure to an inflammatory stimulus $[19,34,35]$. Similar to these studies, we found that LCN2 protein levels in retinal tissues and in cultured Müller cells were significantly increased at $8 \mathrm{~h}$ after LPS treatment, suggesting that LCN2 is likely to be involved in the early response to inflammatory stimuli. It is widely known that LCN2 plays various biological roles in cell survival, apoptosis and iron transport [36]. Previous studies have shown that LCN2 is an important mediator in the regulation of a range of inflammatory diseases, including sepsis, inflammatory bowel disease, and in inflammatory disorders of the central nervous system [19, 37, 38]. However, the specific roles of LCN2 in different inflammatory conditions are not always consistent. For example, Nam et al. found that LCN2 acted in a proinflammatory manner in experimental autoimmune encephalomyelitis models of neuroinflammation [39], and Jang et al. reported that $L c n 2^{-/-}$mice had reduced brain IL-12, TNF- $\alpha$, and IL-23 mRNA levels after LPS injection, suggesting a proinflammatory role LCN2 in the central nervous system [32]. In contrast, Kang et al. found that $L c n 2^{-\gamma^{-}}$mice treated with LPS had significantly elevated levels of proinflammatory cytokines and displayed worse behavioral performance than normal mice [19]. The anti-inflammatory actions of LCN2 are also supported by the finding of Zhang et al. that LCN2 reduced the LPS-induced expression of cytokines by RAW264.7 macrophages [40]. Until now, the specific function of LCN2 in uveitis has not been examined. In the present study, we provide the first evidence that LCN2, a positive acute phase protein, dampens ocular inflammatory reactions.

The ocular inflammation in EIU is characterized by a breakdown of BOB, with inflammatory cell infiltration affecting both the anterior and posterior segments of the eye $[5,6]$. Consistent with this, clinical and histopathological evaluations demonstrated that

\section{KARGER}


LCN2 suppressed inflammatory infiltration into the eyes, indicating that it protects against the disruption of BOB in EIU. This is further supported by the finding that LCN2 inhibited the protein and cell leakage into the AqH caused by LPS. Previous studies have shown that TNF- $\alpha$, IL-6, and MCP- 1 are elevated in the AqH of patients with uveitis and in animal models of uveitis $[41,42]$. TNF- $\alpha$ and IL-6 play key roles in initiating and perpetuating local immune responses [7], and MCP-1 is an important mediator of monocyte infiltration [43]. Our results show that LCN2 reduced the contents of TNF- $\alpha$, IL-6, and MCP-1 in both the AqH and the retina. It has previously been shown that infiltrated leukocytes are the main cellular sources of TNF- $\alpha$, IL-6, and MCP-1 in ocular inflammation [44]. Therefore, the reduced production of these proinflammatory factors in the $\mathrm{AqH}$ and retina may result from the attenuation of leukocyte infiltration. Taken together, these findings suggest that LCN2 inhibits the disruption of on BOB and leukocyte infiltration during the inflammatory processes induced by LPS in vivo.

Müller cells, the main macroglia in the retina, are reported to actively participate in the innate immunity of the retina, especially in infectious conditions [28]. Müller cells have also been identified as the decisive cells in the immune pathology of uveitis [45]. Studies of EIU in rats revealed short-term changes in the Müller cell physiology, indicating that Müller cells play a vital role in uveitis [46]. The gliosis of Müller cells is a well-established response to virtually every retinal disease, and its acute form is usually beneficial, because it tends to be conservative or nonproliferative [47]. Here, we confirmed the acute gliosis of Müller cells and the concomitant upregulation of LCN2 induced by stimulation with LPS in vivo and in vitro. We have also shown that LPS induces the mRNA and protein expression and secretion of TNF-a, IL-6, an MCP-1 in cultured primary Müller cells, whereas LCN2 treatment markedly inhibited their production. Therefore, LCN2 is probably an endogenous anti-inflammatory mediator that acts in an autocrine manner on Müller cells.

The transcription factor NF- $\kappa B$ plays a critical role in the inflammatory and immune responses [48]. In unstimulated cells, NF- $\mathrm{\kappa B}$ is inactive in the cytoplasm. Once stimulated by endotoxins or pro-inflammatory mediators, NF- $\kappa \mathrm{B}$ is phosphorylated and activated. The released p65 subunit then enters the nucleus, where it acts on specific sequences in the promoter regions of its target genes, such as TNFA, IL6, and MCP1 [49-51]. The activation of $\mathrm{NF}-\kappa \mathrm{B}$ by inflammatory stimuli can lead to a cytokine cascade reaction and the exacerbation of the inflammatory responses. Correspondingly, the downregulation of NF- $\kappa B$ activity contributes to the amelioration of inflammatory reactions, including in uveoretinitis [52]. In this study, we found that LCN2 significantly reduced the LPS-induced phosphorylation of p65 at Ser536, which has been shown to change the kinetics of p65 translocation [53]. As we expected, the LPS-induced nuclear translocation of $\mathrm{p} 65$ was also suppressed by LCN2. These results suggest that the inhibition of NF- $\mathrm{BB}$ activation might explain the anti-inflammatory effects of LCN2.

This study had some limitations. EIU resembles acute ocular inflammation, but uveitis can become recurrent or chronic. The role of LCN2 in chronic ocular inflammation remains unclear. A model of chronic human uveitis, such as experimental autoimmune uveoretinitis, is under investigation in our laboratory. Other signaling pathways that may be involved in the anti-inflammatory effects of LCN2 also require clarification.

\section{Conclusion}

In summary, we found that LPS strongly upregulated LCN2 in vivo and in vitro and that LCN2 alleviated ocular inflammation, confirming that LCN2 is a positive acute phase protein. We also identified the possible anti-inflammatory mechanism of LCN2, which acts by suppressing the activation of NF- $\mathrm{KB}$. Considering its small size and simple structure, LCN2 is a potential candidate agent for the treatment of ocular inflammatory diseases in the future. 


\section{Cellular Physiology Cell Physiol Biochem 2018;46:375-388

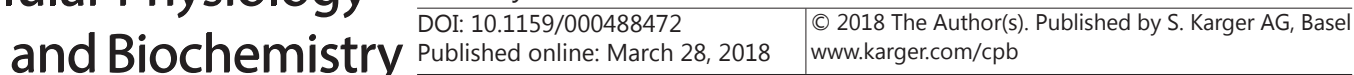 \\ Tang et al.: LCN2 Suppresses Ocular Inflammation in EIU}

\section{Acknowledgements}

This work was supported by research grants from the National Key Basic Research Program of China (2013CB967503), the National Natural Science Foundation of China (81570854), the Youth Project of the National Natural Science Fund (81500723, 81600739) and Science and Technology Commission of Shanghai Municipality (16411953700).

\section{Disclosure Statement}

No conflict of interests exists.

\section{References}

1 Miserocchi E, Fogliato G, Modorati G, Bandello F: Review on the worldwide epidemiology of uveitis. Eur J Ophthalmol 2013;23:705-717.

- Rothova A, Suttorp-van Schulten MS, Frits Treffers W, Kijlstra A: Causes and frequency of blindness in patients with intraocular inflammatory disease. Br J Ophthalmol 1996;80:332-336.

-3 Rosenbaum JT, McDevitt HO, Guss RB, Egbert PR: Endotoxin-induced uveitis in rats as a model for human disease. Nature 1980;286:611-613.

4 Qiu Y, Shil PK, Zhu P, Yang H, Verma A, Lei B, Li Q: Angiotensin-converting enzyme 2 (ACE2) activator diminazene aceturate ameliorates endotoxin-induced uveitis in mice. Invest Ophthalmol Vis Sci 2014;55:3809-3818.

5 McMenamin PG, Crewe J: Endotoxin-induced uveitis. Kinetics and phenotype of the inflammatory cell infiltrate and the response of the resident tissue macrophages and dendritic cells in the iris and ciliary body. Invest Ophthalmol Vis Sci 1995;36:1949-1959.

-6 Xu H, Forrester JV, Liversidge J, Crane IJ: Leukocyte trafficking in experimental autoimmune uveitis: breakdown of blood-retinal barrier and upregulation of cellular adhesion molecules. Invest Ophthalmol Vis Sci 2003;44:226-234.

7 de Vos AF, van Haren MA, Verhagen C, Hoekzema R, Kijlstra A: Kinetics of intraocular tumor necrosis factor and interleukin-6 in endotoxin-induced uveitis in the rat. Invest Ophthalmol Vis Sci 1994;35:11001106.

8 Tuaillon N, Shen DF, Berger RB, Lu B, Rollins BJ, Chan CC: MCP-1 expression in endotoxin-induced uveitis. Invest Ophthalmol Vis Sci 2002;43:1493-1498.

-9 Siddique SS, Shah R, Suelves AM, Foster CS: Road to remission: a comprehensive review of therapy in uveitis. Expert Opin Investig Drugs 2011;20:1497-1515.

10 Oray M, Abu Samra K, Ebrahimiadib N, Meese H, Foster CS: Long-term side effects of glucocorticoids. Expert Opin Drug Saf 2016;15:457-465.

11 Flower DR: The lipocalin protein family: structure and function. Biochem J 1996;318:1-14.

-12 Goetz DH, Holmes MA, Borregaard N, Bluhm ME, Raymond KN, Strong RK: The neutrophil lipocalin NGAL is a bacteriostatic agent that interferes with siderophore-mediated iron acquisition. Mol Cell 2002;10:10331043.

13 Lee S, Lee WH, Lee MS, Mori K, Suk K: Regulation by lipocalin-2 of neuronal cell death, migration, and morphology. J Neurosci Res 2012;90:540-550.

14 Marques F, Rodrigues AJ, Sousa JC, Coppola G, Geschwind DH, Sousa N, Correia-Neves M, Palha JA: Lipocalin 2 is a choroid plexus acute-phase protein. J Cereb Blood Flow Metab 2008;28:450-455.

15 Jeon S, Jha MK, Ock J, Seo J, Jin M, Cho H, Lee WH, Suk K: Role of lipocalin-2-chemokine axis in the development of neuropathic pain following peripheral nerve injury. J Biol Chem 2013;288:24116-24127.

16 Bachman MA, Miller VL, Weiser JN: Mucosal lipocalin 2 has pro-inflammatory and iron-sequestering effects in response to bacterial enterobactin. PLoS Pathog 2009;5:e1000622.

17 Shao S, Cao T, Jin L, Li B, Fang H, Zhang J, Zhang Y, Hu J, Wang G: Increased Lipocalin-2 Contributes to the Pathogenesis of Psoriasis by Modulating Neutrophil Chemotaxis and Cytokine Secretion. J Invest Dermatol 2016;136:1418-1428. 


\section{Cellular Physiology Cell Physiol Biochem 2018;46:375-388

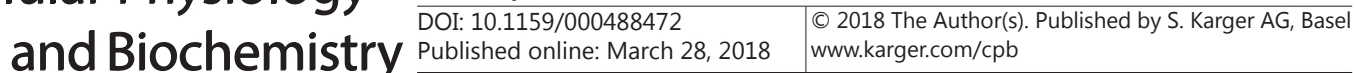 \\ Tang et al.: LCN2 Suppresses Ocular Inflammation in EIU}

18 Naude PJ, Nyakas C, Eiden LE, Ait-Ali D, van der Heide R, Engelborghs S, Luiten PG, De Deyn PP, den Boer JA, Eisel UL: Lipocalin 2: novel component of proinflammatory signaling in Alzheimer's disease. FASEB J 2012;26:2811-2823.

19 Kang SS, Ren Y, Liu CC, Kurti A, Baker KE, Bu G, Asmann Y, Fryer JD: Lipocalin-2 protects the brain during inflammatory conditions. Mol Psychiatry DOI: 10.1038/mp.2016.243.

-20 Guglani L, Gopal R, Rangel-Moreno J, Junecko BF, Lin Y, Berger T, Mak TW, Alcorn JF, Randall TD, Reinhart TA, Chan YR, Khader SA: Lipocalin 2 regulates inflammation during pulmonary mycobacterial infections. PLoS One 2012;7:e50052.

-21 Berard JL, Zarruk JG, Arbour N, Prat A, Yong VW, Jacques FH, Akira S, David S: Lipocalin 2 is a novel immune mediator of experimental autoimmune encephalomyelitis pathogenesis and is modulated in multiple sclerosis. Glia 2012;60:1145-1159.

22 Ye X, Ren H, Zhang M, Sun Z, Jiang AC, Xu G: ERK1/2 signaling pathway in the release of VEGF from Muller cells in diabetes. Invest Ophthalmol Vis Sci 2012;53:3481-3489.

23 Anfuso CD, Olivieri M, Fidilio A, Lupo G, Rusciano D, Pezzino S, Gagliano C, Drago F, Bucolo C: Gabapentin Attenuates Ocular Inflammation: In vitro and In vivo Studies. Front Pharmacol 2017;8:173.

24 Ruiz-Moreno JM, Thillaye B, de Kozak Y: Retino-choroidal changes in endotoxin-induced uveitis in the rat. Ophthalmic Res 1992;24:162-168.

25 Vaughan DK, Lasater EM: Glial and neuronal markers in bass retinal horizontal and Muller cells. Brain Res 1990;537:131-140.

-26 Planck SR, Huang XN, Robertson JE, Rosenbaum JT: Cytokine mRNA levels in rat ocular tissues after systemic endotoxin treatment. Invest Ophthalmol Vis Sci 1994;35:924-930.

27 Adamus G, Machnicki M, Amundson D, Adlard K, Offner H: Similar pattern of MCP-1 expression in spinal cords and eyes of Lewis rats with experimental autoimmune encephalomyelitis associated anterior uveitis. J Neurosci Res 1997;50:531-538.

28 Kumar A, Shamsuddin N: Retinal Muller glia initiate innate response to infectious stimuli via toll-like receptor signaling. PLoS One 2012;7:e29830.

29 Jeon CJ, Strettoi E, Masland RH: The major cell populations of the mouse retina. J Neurosci 1998;18:89368946.

30 Li Q Verma IM: NF-kappaB regulation in the immune system. Nat Rev Immunol 2002;2:725-734.

31 Lee S, Park JY, Lee WH, Kim H, Park HC, Mori K, Suk K: Lipocalin-2 is an autocrine mediator of reactive astrocytosis. J Neurosci 2009;29:234-249.

-32 Jang E, Lee S, Kim JH, Kim JH, Seo JW, Lee WH, Mori K, Nakao K, Suk K: Secreted protein lipocalin-2 promotes microglial M1 polarization. FASEB J 2013;27:1176-1190.

-33 Hamzic N, Blomqvist A, Nilsberth C: Immune-induced expression of lipocalin-2 in brain endothelial cells: relationship with interleukin-6, cyclooxygenase-2 and the febrile response. J Neuroendocrinol 2013;25:271-280.

34 Jang E, Kim JH, Lee S, Kim JH, Seo JW, Jin M, Lee MG, Jang IS, Lee WH, Suk K: Phenotypic polarization of activated astrocytes: the critical role of lipocalin-2 in the classical inflammatory activation of astrocytes. J Immunol 2013;191:5204-5219.

-35 Jin M, Kim JH, Jang E, Lee YM, Soo Han H, Woo DK, Park DH, Kook H, Suk K: Lipocalin-2 deficiency attenuates neuroinflammation and brain injury after transient middle cerebral artery occlusion in mice. J Cereb Blood Flow Metab 2014;34:1306-1314.

-36 Jha MK, Lee S, Park DH, Kook H, Park KG, Lee IK, Suk K: Diverse functional roles of lipocalin-2 in the central nervous system. Neurosci Biobehav Rev 2015;49:135-156.

37 Ostvik AE, Granlund AV, Torp SH, Flatberg A, Beisvag V, Waldum HL, Flo TH, Espevik T, Damas JK, Sandvik AK: Expression of Toll-like receptor-3 is enhanced in active inflammatory bowel disease and mediates the excessive release of lipocalin 2. Clin Exp Immunol 2013;173:502-511.

-38 Ferreira AC, Da Mesquita S, Sousa JC, Correia-Neves M, Sousa N, Palha JA, Marques F: From the periphery to the brain: Lipocalin-2, a friend or foe? Prog Neurobiol 2015;131:120-136.

-39 Nam Y, Kim JH, Seo M, Kim JH, Jin M, Jeon S, Seo JW, Lee WH, Bing SJ, Jee Y, Lee WK, Park DH, Kook H, Suk K: Lipocalin-2 protein deficiency ameliorates experimental autoimmune encephalomyelitis: the pathogenic role of lipocalin-2 in the central nervous system and peripheral lymphoid tissues. J Biol Chem2014;289:16773-16789. 


\section{Cellular Physiology Cell Physiol Biochem 2018;46:375-388 \begin{tabular}{c|c|c|} 
DOI: 10.1159/000488472 & and Biochemistry & $\begin{array}{l}\text { O 2018 The Author(s). Published by S. Karger AG, Basel } \\
\text { wwww.karger.com/cpb }\end{array}$
\end{tabular}

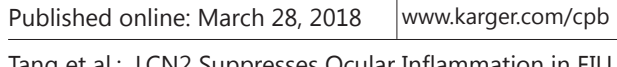

40 Zhang J, Wu Y, Zhang Y, Leroith D, Bernlohr DA, Chen X: The role of lipocalin 2 in the regulation of inflammation in adipocytes and macrophages. Mol Endocrinol 2008;22:1416-1426.

-41 Curnow SJ, Falciani F, Durrani OM, Cheung CM, Ross EJ, Wloka K, Rauz S, Wallace GR, Salmon M, Murray PI: Multiplex bead immunoassay analysis of aqueous humor reveals distinct cytokine profiles in uveitis. Invest Ophthalmol Vis Sci 2005;46:4251-4259.

42 Kalariya NM, Shoeb M, Ansari NH, Srivastava SK, Ramana KV: Antidiabetic drug metformin suppresses endotoxin-induced uveitis in rats. Invest Ophthalmol Vis Sci 2012;53:3431-3440.

-43 Lu B, Rutledge BJ, Gu L, Fiorillo J, Lukacs NW, Kunkel SL, North R, Gerard C, Rollins BJ: Abnormalities in monocyte recruitment and cytokine expression in monocyte chemoattractant protein 1-deficient mice. J Exp Med 1998;187:601-608.

-44 Crane IJ, McKillop-Smith S, Wallace CA, Lamont GR, Forrester JV: Expression of the chemokines MIP-1alpha, MCP-1, and RANTES in experimental autoimmune uveitis. Invest Ophthalmol Vis Sci 2001;42:1547-1552.

45 Chan CC, Roberge FG, Ni M, Zhang W, Nussenblatt RB: Injury of Muller cells increases the incidence of experimental autoimmune uveoretinitis. Clin Immunol Immunopathol 1991;59:201-207.

-46 Takeda M, Takamiya A, Yoshida A, Kiyama H: Extracellular signal-regulated kinase activation predominantly in Muller cells of retina with endotoxin-induced uveitis. Invest Ophthalmol Vis Sci 2002;43:907-911.

-47 Bringmann A, Iandiev I, Pannicke T, Wurm A, Hollborn M, Wiedemann P, Osborne NN, Reichenbach A: Cellular signaling and factors involved in Muller cell gliosis: neuroprotective and detrimental effects. Prog Retin Eye Res 2009;28:423-451.

48 Siebenlist U, Franzoso G, Brown K: Structure, regulation and function of NF-kappa B. Annu Rev Cell Biol 1994;10:405-455.

-49 Bird TA, Schooley K, Dower SK, Hagen H, Virca GD: Activation of nuclear transcription factor NF-kappaB by interleukin-1 is accompanied by casein kinase II-mediated phosphorylation of the p65 subunit. The Journal of biological chemistry 1997;272:32606-32612.

50 Parikh AA, Salzman AL, Kane CD, Fischer JE, Hasselgren PO: IL-6 production in human intestinal epithelial cells following stimulation with IL-1 beta is associated with activation of the transcription factor NF-kappa B. J Surg Res 1997;69:139-144.

51 Martin T, Cardarelli PM, Parry GC, Felts KA, Cobb RR: Cytokine induction of monocyte chemoattractant protein-1 gene expression in human endothelial cells depends on the cooperative action of NF-kappa B and AP-1. Eur J Immunol 1997;27:1091-1097.

52 Kubota S, Kurihara T, Mochimaru H, Satofuka S, Noda K, Ozawa Y, Oike Y, Ishida S, Tsubota K: Prevention of ocular inflammation in endotoxin-induced uveitis with resveratrol by inhibiting oxidative damage and nuclear factor-kappaB activation. Invest Ophthalmol Vis Sci 2009;50:3512-3519.

53 Sakurai H, Chiba H, Miyoshi H, Sugita T, Toriumi W: IkappaB kinases phosphorylate NF-kappaB p65 subunit on serine 536 in the transactivation domain. J Biol Chem 1999;274:30353-30356. 